\title{
Studi Kasus Karakteristik Kepribadian Pasien Skizofrenia Paranoid Ditinjau dari Minnesota Multiphasic Personality Inventory-2 (MMPI-2)
}

\author{
Rikza Novita Muna'amah \\ Magister Psikologi Profesi, Fakultas Psikologi, Universitas Surabaya \\ rikzanovita@gmail.com \\ Elly Yuliandari Gunatirin \\ Magister Psikologi Profesi, Fakultas Psikologi, Universitas Surabaya \\ ellyyuliandari@gmail.com
}

\begin{abstract}
The personality of paranoid schizophrenia patients is certainly different and has its own peculiarities, therefore, some personality tests are needed so that the diagnosis and application of the intervention can be on target. One of the measuring instruments which widely used is the Minnesota Multiphasic Personality Inventory-2 (MMPI-2). The purpose of this study was to study the personality characteristics of paranoid schizophrenia patients that reviewed with the Minnesota Multiphasic Personality Inventory-2 (MMPI-2). The sampling technique used purposive sampling with one patient. Paranoid schizophrenia has personality characteristics of the type Schizophrenia $(\mathrm{Sc})(94=$ very high) and Paranoia $(\mathrm{Pa})(83=$ very high). These patients often have delusions and hallucinations, making it difficult to determine reality and fantasy.
\end{abstract}

Keywords: paranoid schizophrenia; personality tests; MMPI

\begin{abstract}
Abstrak
Kepribadian pasien skizofrenia paranoid tentu berbeda dan memiliki kekhasan tersendiri, sehingga memerlukan suatu tes kepribadian agar diagnosa dan penerapan intervensi dapat tepat sasaran. Salah satu alat ukur yang digunakan adalah Minnesota Multiphasic Personality Inventory-2 (MMPI-2). Tujuan dari penelitian ini adalah untuk mengetahui karakteristik kepribadian dari pasien skizofrenia paranoid yang ditinjau dari Minnesota Multiphasic Personality Inventory-2 (MMPI-2). Teknik pengambilan sampel menggunakan purposive sampling dengan besar sampel 1 orang pasien. Hasil dari penelitian ini menunjukkan bahwa pasien skizofrenia paranoid memiliki karakteristik kepribadian kecenderungan tipe Schizophrenia (Sc) $(94=$ extremely high $)$ dan Paranoia $(\mathrm{Pa})(83=$ very high $)$. Pasien ini sering kali mengalami waham dan halusinasi yang kuat, sehingga kesulitan untuk membedakan realita dan fantasi.
\end{abstract}

Kata kunci: skizofrenia paranoid; tes kepribadian; MMPI 


\section{Pendahuluan}

Skizofrenia merupakan gangguan mental berat yang membuat kondisi emosi, pikiran, dan perilaku dari pasien tersebut mengalami gangguan. Menurut Maramis (2009), skizofrenia adalah suatu psikosa fungsional dengan gangguan utama pada proses pikir serta disharmonisasi antara proses pikir, afek atau emosi, kemauan dan psikomotor disertai distorsi kenyataaan terutama karena waham dan halusinasi, assosiasi terbagi-bagi sehingga muncul inkoherensi, afek dan emosi inadekuat, psikomotor menunjukkan penarikan diri, ambivalensi dan perilaku bizar. Berdasarkan data yang dihimpun oleh WHO (2016), 21 juta orang mengalami skizofrenia. Sedangkan menurut Riskesdas (2018), sebanyak 7\% penduduk di Indonesia mengalami skizofrenia.

Skizofrenia memiliki beberapa jenis, yakni paranoid, katatonik, hebefrenik, dan undifferentiated, dan residual. Pada penelitian ini, peneliti akan berfokus pada skizofrenia tipe paranoid. Berdasarkan DSM-IV TR (2000), skizofrenia paranoid memiliki gejala seperti waham (delusi) (waham kebesaran, waham kejar, dan sebagainya), halusinasi (auditori, visual, penciuman, dan sebagainya), serta gangguan afektif berupa dorongan kehendak dan berbicara yang relatif tidak menonjol. Salah satu alat ukur yang kerap digunakan untuk melihat karakteristik kepribadian dari pasien skizofrenia adalah menggunakan Minnesota Multiphasic Personality Inventory (MMPI). Alat ukur MMPI digunakan secara luas untuk mengasesmen kepribadian secara klinis (MMPI; Dahlstrom \& Welsh, 1960; MMPI-2; Butcher, Dahlstrom, Graham, Tellegen, \& Kaemmer, 1989), selain itu, berbagai studi menunjukkan validitas dan penggunaan MMPI untuk mengasesmen kasus-kasus psikosis (Butcher, 2000; Exner, 1993; Kleiger, 1999). Penelitian dari Carter et al. (1999) menemukan bahwa skala MMPI sangat memiliki keterkaitan dengan skizofrenia. Berdasarkan pernyataan di atas, peneliti ingin membahas mengenai dinamika kepribadian dari pasien skizofrenia paranoid ditinjau dari MMPI. 


\section{Metode}

Jenis penelitian ini adalah kualitatif dengan satu orang partisipan. Pemilihan partisipan menggunakan purposive sampling yaitu peneliti memilih partisipan sesuai dengan tujuan tertentu. Menurut Sugiyono (2010) pengertian purposive sampling yakni suatu teknik untuk menentukan sampel penelitian dengan beberapa pertimbangan tertentu yang bertujuan agar data yang diperoleh nantinya bisa lebih representatif. Kriteria pemilihan partisipan yaitu pasien skizofrenia yang telah didiagnosa secara medis mengalami skizofrenia paranoid dari sebuah rumah sakit jiwa di Surabaya.

Pada penelitian ini, partisipan bernama Eros (inisial) memiliki riwayat kekambuhan sebanyak 4kali. Gangguan yang dirasakan Eros dimulai saat ia masih anak-anak. Ia seringkali mengalami sakit kepala hebat. Eros juga mengalami kejang sebanyak 3 kali selama hidupnya. Setelah itu, mulai munculnya halusinasi dan waham yang dirasakan oleh Eros. Hasil pemeriksaan di RSJ Menur adalah gangguan kepribadian, sedangkan hasil asesmen yang dilakukan menunjukkan adanya simptom halusinasi auditori yang kuat dan visual, serta beberapa simtom negatif, sehingga ditegakkan diagnosa skizofrenia.

Berikut merupakan identitas diri dari partisipan, yaitu :

$\begin{array}{ll}\text { Nama (Inisial) } & \text { : Eros } \\ \text { Jenis Kelamin } & \text { : Laki-laki } \\ \text { Tempat/Tanggal Lahir } & : \text { Surabaya, 06 Maret } 1964 \\ \text { Usia } & : 54 \text { tahun } \\ \text { Alamat (Inisial) } & : \text { Surabaya } \\ \text { Pendidikan/Pekerjaan } & : \text { SMA/Tidak bekerja } \\ \text { Agama } & : \text { Islam } \\ \text { Suku Bangsa } & : \text { Jawa } \\ \text { Latar Belakang Budaya } & : \text { Jawa } \\ \text { Urutan Kelahiran } & : 4 \text { dari 5 bersaudara } \\ \text { Status Perkawinan } & : \text { Belum Kawin } \\ \text { Kasus Medis } & : \text { Skizofrenia Paranoid }\end{array}$


Riwayat Masuk RSJ

:a). 19 April 1986

: b). 6 Juli 2014 - 25 Juli 2014

:c). 29 Agustus 2017 - 9 September 2017

:d). 20 Maret 2018 - 5 April 2018

\section{Hasil dan Pembahasan}

Tabel 1. Hasil Pemeriksaan MMPI-2

\begin{tabular}{ccc}
\hline & Hasil & \\
\hline Keterangan & T Score & Raw Score \\
\hline VRIN & 61 & 8 \\
\hline TRIN & 107 & 1 \\
\hline F & 104 & 22 \\
\hline F(B) & 42 & 42 \\
\hline F(P) & 9 & 9 \\
\hline L & 74 & 9 \\
\hline K & 39 & 10 \\
\hline S & 41 & 17 \\
\hline Hs & 51 & 13 \\
\hline D & 66 & 26 \\
\hline Hy & 57 & 24 \\
\hline Pd & 70 & 24 \\
\hline Mf & 42 & 22 \\
\hline Pa & 83 & 19 \\
\hline Pt & 74 & 38 \\
\hline Sc & 94 & 52 \\
\hline Ma & 69 & 27 \\
\hline Si & 70 & 43 \\
\hline
\end{tabular}


Grafik 1. Validitas dan Profil SkalaKlinis MMPI-2

MMPI-2 VALIDITY AND CLINICAL SCALES PROFILE

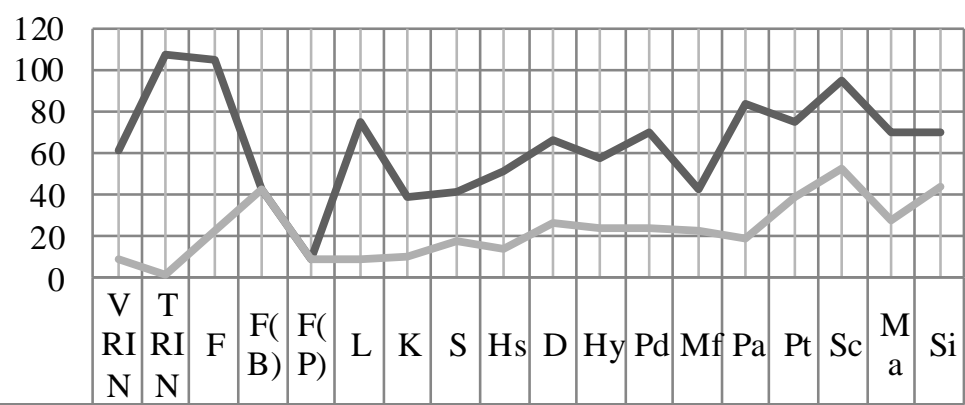

\begin{tabular}{l|l|lll|l|l|l|l|l|l|l|l|l|l|l|l|l} 
T Score & 61 & 107104 & 42 & 9 & 74 & 39 & 41 & 51 & 66 & 57 & 70 & 42 & 83 & 74 & 94 & 69 & 70
\end{tabular}

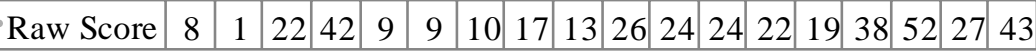

Tabel 2. Komposisi Standar Validitas dan Profil Skala Klinis

\begin{tabular}{|c|c|c|c|c|}
\hline Scale & Input & Raw Score & $\begin{array}{l}\text { T Score } \\
\text { (Male) }\end{array}$ & $\begin{array}{l}\text { Klasifikasi } \\
\text { Laki-Laki }\end{array}$ \\
\hline L Scale & 9 & 9 & 74 & High \\
\hline F Scale & 22 & 22 & 104 & Extremely High \\
\hline Fb Scale & 17 & 17 & 112 & Extremely High \\
\hline Fp Scale & 9 & 9 & 106 & Extremely High \\
\hline K Scale & 10 & 10 & 39 & Very Low \\
\hline S Scale & 17 & 17 & 41 & Moderately Low \\
\hline Scale 1 - Hypochondriasis (Hs) & 8 & 13 & 51 & Average \\
\hline Scale 2 - Depression (D) & 26 & 26 & 66 & $\begin{array}{l}\text { Moderately } \\
\text { High }\end{array}$ \\
\hline Scale 3 - Hysteria (Hy) & 24 & 24 & 57 & Average \\
\hline Scale 4 - Psychopatic Deviate $(\mathrm{Pd})$ & 20 & 24 & 70 & High \\
\hline Scale 5 - Masculinity - Femininity (Male) & 22 & 22 & 42 & Moderately Low \\
\hline Scale 5 - Masculinity - Femininity (Female) & 22 & 22 & & \\
\hline Scale 6 - Paranoia $(\mathrm{Pa})$ & 19 & 19 & 83 & Very High \\
\hline Scale 7 - Psychasthenia $(\mathrm{Pt})$ & 28 & 38 & 74 & High \\
\hline Scale 8 - Schizophrenia $(\mathrm{Sc})$ & 42 & 52 & 94 & Extremely High \\
\hline Scale 9 - Hypomania (Ma) & 25 & 27 & 69 & $\begin{array}{c}\text { Moderately } \\
\text { High }\end{array}$ \\
\hline Scale 0 - Social Introversion $(\mathrm{Si})$ & 43 & 43 & 70 & High \\
\hline FB Scale & 42 & 42 & & \\
\hline FP Scale & 9 & 9 & & \\
\hline VRIN & 8 & 8 & 61 & $\begin{array}{c}\text { Moderately } \\
\text { High }\end{array}$ \\
\hline TRIN & 1 & 1 & 107 & Extremely High \\
\hline
\end{tabular}


Tabel 3. Komposisi dari Subskala Harris-Lingoes

\begin{tabular}{|c|c|c|c|c|}
\hline Scale & Input & $\begin{array}{l}\text { Raw } \\
\text { Score }\end{array}$ & $\begin{array}{l}\text { T Score } \\
\text { (Male) }\end{array}$ & $\begin{array}{c}\text { klasifikasi } \\
\text { Laki-laki }\end{array}$ \\
\hline \multicolumn{5}{|l|}{ Scale 2 - Depression } \\
\hline D1 - Subjective Depression & 17 & 17 & 77 & High \\
\hline D2 - Psychomotor Retardation & 8 & 8 & 65 & $\begin{array}{c}\text { Moderately } \\
\text { High }\end{array}$ \\
\hline D3 - Physical Malfunction & 4 & 4 & 59 & Average \\
\hline D4 - Mental Dullness & 6 & 6 & 67 & $\begin{array}{c}\text { Moderately } \\
\text { High }\end{array}$ \\
\hline D5 - Brooding & 6 & 6 & 64 & $\begin{array}{c}\text { Moderately } \\
\text { High }\end{array}$ \\
\hline \multicolumn{5}{|l|}{ Scale 3 - Hysteria } \\
\hline Hy1 - Denial of Social Anxiety & 2 & 2 & 40 & $\begin{array}{c}\text { Moderately } \\
\text { Low } \\
\end{array}$ \\
\hline Hy2 - Need for Affection & 5 & 5 & 43 & $\begin{array}{c}\text { Moderately } \\
\text { Low } \\
\end{array}$ \\
\hline Hy3 - Lassitude-malaise & 5 & 5 & 61 & $\begin{array}{c}\text { Moderately } \\
\text { High }\end{array}$ \\
\hline Hy4 - Somatic Complaints & 7 & 7 & 72 & High \\
\hline Hy5 - Inhibition of Aggression & 3 & 3 & 48 & $\begin{array}{c}\text { Moderately } \\
\text { Low }\end{array}$ \\
\hline \multicolumn{5}{|l|}{ Scale 4 - Psychopatic Deviate } \\
\hline Pd1 - Familial Discord & 1 & 1 & 38 & Very Low \\
\hline Pd2 - Authority Problems & 2 & 2 & 35 & Very Low \\
\hline Pd3 - Social Imperturbability & 2 & 2 & 35 & Very Low \\
\hline Pd4 - Social Alienation & 9 & 9 & 77 & High \\
\hline Pd5 - Self-alienation & 8 & 8 & 73 & High \\
\hline \multicolumn{5}{|l|}{ Scale 6 - Paranoia } \\
\hline Pa1 - Persecutory Ideas & 9 & 9 & 94 & $\begin{array}{c}\text { Extremely } \\
\text { High }\end{array}$ \\
\hline $\mathrm{Pa} 2$ - Poiganancy & 3 & 3 & 55 & Average \\
\hline Pa3 - Naivete & 3 & 3 & 41 & $\begin{array}{c}\text { Moderately } \\
\text { Low }\end{array}$ \\
\hline \multicolumn{5}{|l|}{ Scale 8 - Schizophrenia } \\
\hline Sc1 - Social Alienation & 9 & 9 & 76 & High \\
\hline Sc2 - Emotional Alienation & 5 & 5 & 88 & Very High \\
\hline Sc3 - Lack of eg Mastery. Cognitive & 8 & 8 & 90 & $\begin{array}{c}\text { Extremely } \\
\text { High }\end{array}$ \\
\hline Sc4 - Lack of Ego Mastery, Conative & 8 & 8 & 82 & Very High \\
\hline Sc5 - Lack of Ego mastery, Defective Inhib. & 6 & 6 & 82 & Very High \\
\hline Sc6 - Bizarre Sensory Experience & 10 & 10 & 90 & $\begin{array}{c}\text { Extremely } \\
\text { High }\end{array}$ \\
\hline \multicolumn{5}{|l|}{ Scale 9 - Hypomania } \\
\hline Ma1 - Amorality & 1 & 1 & 30 & Very Low \\
\hline \multicolumn{5}{|c|}{ Bersambung ........ } \\
\hline
\end{tabular}




\begin{tabular}{l|c|c|c|c}
\hline \multicolumn{2}{c}{ Lanjutan ....... } \\
\hline Ma2 - psychomotor Acceleration & 7 & 7 & 58 & Average \\
\hline Ma3 - Imperturbability & 4 & 4 & 53 & Average \\
\hline Ma4 - Ego Inflation & 7 & 7 & 76 & High \\
\hline FB Scale & & & 0 & \\
\hline FP Scale & & & 106 & \\
\hline
\end{tabular}

Eros memiliki kecenderungan tipe Schizophrenia $(S c)(94=$ extremely high $)$ dan Paranoia $(\mathrm{Pa})(83=$ very high $)$. Biasanya, individu yang didiagnosa dengan tipe 86 mengalami skizofrenia tipe paranoid. Hal ini ditandai dengan perilaku psikotik yang nampak, sulit berkonsentrasi, isi pikiran yang aneh karena ide yang terpecah-pecah, tidak langsung, dan lambat. Delusi, merasa tidak nyata, afeksi yang kabur, bicara cepat dan tidak sesuai, pertahanan diri yang buruk, reaksi atas stres dan tekanan yang diatasi dengan menarik diri pada fantasi dan berangan-angan, sehingga sering kali kesulitan membedakan yang fantasi dan realitas.

Eros juga sangat sering merasakan tidak aman dan inferior, kurang memiliki kepercayaan diri dan harga diri, mudah merasa bersalah saat melakukan kesalahan, menarik diri dari aktivitas, dan apatis. Eros memiliki ide-ide tentang bunuh diri, mudah curiga dan tidak percaya, menghindari ikatan emosional yang mendalam, sangat nyaman jika sendiri dan tidak ingin bergaul dengan lingkungan, mudah berubah perasaan, merasa terganggu, dan pandangannya selalu negatif terhadap apapun.

\section{Kesimpulan dan Saran}

Hasil penelitian ini menunjukkan bahwa pasien yang mengalami skizofrenia akan memiliki 2 skor tertinggi untuk kategori Sc dan Pa. Perilaku yang ditunjukan adalah sulit berkonsentrasi, memiliki isi pikirannya dipenuhi dengan ide-ide, namun tidak terbentuk suatu konstruk berpikir yang utuh. Kondisi ini jug diperparah dengan kondisi afeksinya yang buruk, serta kurangnya kemampuan untuk bertahan pada kondisi stres. Kecenderungannya lebih suka menarik diri pada realitas, sehingga lebih nyaman hidup dalam bayangan fantasi. 
Hal ini yang menjadi penyebab pasien skizofrenia paranoid kesulitan membedakan fantasi dan realitas. Rekomendasi yang dapat diberikan pada keluarga pasien, yakni pendampingan secara berkala agar terdistraksi dari delusi dan halusinasinya. Selain itu, pasien juga perlu diperhatikan dalam mengkonsumsi obat-obatan, agar dapat menghindari relapse.

\section{DAFTAR PUSTAKA}

APA. (2000). DSM V-TR (Diagnostic and Statistical Manual of Mental Disorders IV Text Revision).

Butcher, J. N. (Ed.). (2000). Basic sources on the MMPI-2. Minneapolis: University of Minnesota Press.

Butcher, J. N., Dahlstrom, W. G., Graham, J. R., Tellegen, Y. S., \& Kaemmer, B. (1989). Minnesota Multiphasic Personality Inventory-2, user's guide, the Minnesota report: Adult clinical system. Minneapolis, MN: National Computer Systems.

Carter, J. W., Parnas, J., Cannon, T. D., Schulsinger, F., \& Mednick, S. A. (1999). MMPI variables predictive of schizophrenia in the Copenhagen High-Risk Project: a 25-year follow-up. Acta Psychiatrica Scandinavica, 99(6), 432440. doi:10.1111/j.1600-0447.1999.tb00989.x

Dahlstrom,W. G., \&Welsh, G. S. (1960). An MMPI handbook: A guide to use in clinical practice and research. Minneapolis: University of Minnesota Press.

Exner, J. E., Jr. (1993). The Rorschach: A Comprehensive System: Vol. 1. Basic foundations (3rd ed.). New York: Wiley.

Kemenkes RI. Riset Kesehatan Dasar (RISKESDAS) 2018. Badan Penelitian dan Pengembangan Kesehatan Kementerian Kesehatan Republik Indonesia. Jakarta : Kementerian Kesehatan Republik Indonesia. 2018.

Kleiger, J. H. (1999). Disordered thinking and the Rorschach. Hillsdale, NJ: The Analytic Press.

Maramis, W. E. (1980). Ilmu Kedokteran Jiwa. Airlangga University Press: Surabaya.

Sugiyono. 2010. Metode Penelitian Pendidikan Pendekatan Kuantitatif, kualitatif, dan $R \& D$. Bandung: Alfabeta. 